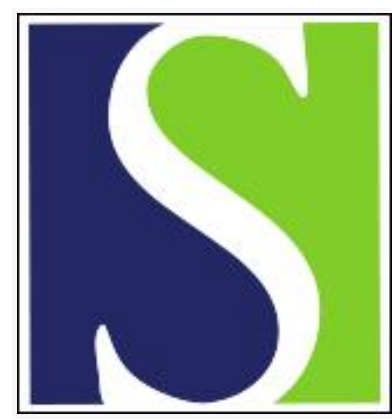

Scand J Work Environ Health 2003;29(1):40-50

https://doi.org/10.5271/sjweh.703

Issue date: Feb 2003

Annoyance and performance during the experimental chemical challenge of subjects with multiple chemical sensitivity

by Österberg K, Ørbæk P, Karlson B, Åkesson B, Bergendorf U

Affiliation: Department of Occupational and Environmental Medicine, Lund University Hospital, SE 22185 Lund, Sweden. kai.osterberg@ymed.lu.se

Refers to the following texts of the Journal: 1998;24(5):432-438 2000;26(3):219-226

The following article refers to this text: 2004;30(6):486-496

Key terms: annoyance; cacosmia; experimental chemical challenge; exposure chamber; idiopathic environmental intolerance; multiple chemical sensitivity; neuropsychological test; performance

This article in PubMed: www.ncbi.nlm.nih.gov/pubmed/12630435

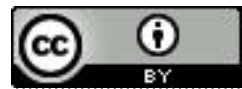




\title{
Annoyance and performance during the experimental chemical challenge of subjects with multiple chemical sensitivity
}

\author{
by Kai Österberg, PhD, ${ }^{1}$ Palle Ørbæk, MD, ${ }^{1}$ Björn Karlson, PhD, ${ }^{1}$ Bengt Åkesson, PhD, ${ }^{1}$ \\ Ulf Bergendorf, MscChE'
}

\begin{abstract}
Österberg K, Ørbæk P, Karlson B, Åkesson B, Bergendorf U. Annoyance and performance during the experimental chemical challenge of subjects with multiple chemical sensitivity. Scand J Work Environ Health 2003;29(1):40 50 .
\end{abstract}

\begin{abstract}
Objectives This study explored the subjective reactions and psychological test performance of smell-intolerant subjects during consecutive challenges to chemicals with contrasting neurotoxic properties.

Methods Women with symptoms compatible with multiple chemical sensitivity $(\mathrm{N}=10)$ and healthy referents $(\mathrm{N}=20)$ were individually challenged in an exposure chamber. All the subjects attended two separate 2-hour sessions of exposure to n-butyl acetate and toluene, in counterbalanced sequence. After an initial phase without exposure, air concentrations were increased in steps ranging from 3.6 to $57 \mathrm{mg} / \mathrm{m}^{3}$ for n-butyl acetate and from 11 to $180 \mathrm{mg} / \mathrm{m}^{3}$ for toluene. The response measures comprised ratings of annoyance and smell intensity and also neurobehavioral test performance.
\end{abstract}

Results Both groups showed an increase in annoyance ratings and a decrease in test performance in the initial unexposed chamber phase and also in the first phase of the chemical exposure, these results indicating slight immediate expectancy or "suggestion" effects. During the six chamber phases, the ratings of mucous membrane irritation and fatigue showed a steeper increase in the group with multiple chemical sensitivity than among the referents, while the ratings of smell intensity and smell annoyance were similar in the two groups. A reduction in test performance was observed during the chamber phases, particularly in the group with multiple chemical sensitivity. No relation was found between the ratings or performance and chemical substance.

Conclusions Stronger immediate expectancy or "suggestion" reactions than normal did not characterize the group with multiple chemical sensitivity. This group showed a stronger than normal gradual build-up of fatigue, mucous membrane irritation, and reduced performance during chemical exposure. The results offer the most support to an irritative basis for multiple chemical sensitivity.

Key terms cacosmia, exposure chamber, idiopathic environmental intolerance, neuropsychological tests.

Multiple chemical sensitivity, also known as idiopathic environmental intolerance, is a condition of acquired intolerance to a broad range of chemical smells. The underlying mechanisms are still not agreed upon; several competing explanations exist. The negligible previous exposure to neurotoxins found in most cases of this condition does not fit a traditional neurotoxic explanation, nor has it been possible to demonstrate a traditional respiratory disorder, allergy mediated by immunoglobulin $\mathrm{E}$, or other immune system dysregulation or dysfunction in relation to multiple chemical sensitivity (1). Current evidence points to a significant psychogenic com- ponent or, possibly, to a combination of psychological, psychophysiological, and neurobiological factors (2-4).

One way of studying this controversial condition is through experimental chemical provocation (5-6). We have previously developed a method for studying intolerance to chemical smells commonly observed in cases of chronic toxic encephalopathy after long-term solvent exposure. The toxic encephalopathy group showed a reproducible pattern of elevated annoyance reactions during chemical challenge, but without a parallel decline in psychological performance tests (7-8). In our present study, we applied the same provocation method to a

Division of Occupational and Environmental Medicine, Department of Laboratory Medicine, Lund University, Sweden.

Reprint requests to: Dr Kai Österberg, Department of Occupational and Environmental Medicine, Lund University Hospital, SE-221 85 Lund, Sweden. [E-mail: kai.osterberg@ymed.lu.se] 
group of patients with multiple chemical sensitivity, with the aim of exploring self-ratings of smell intensity and annoyance, as well as psychological test performance. Specifically, we addressed the issue of whether multiple chemical sensitivity would show a discrepant and unique pattern of reactions when compared with toxic encephalopathy.

\section{Subjects and methods}

\section{Subjects}

The group with multiple chemical sensitivity was comprised of patients with chronic subjective intolerance reactions to chemical smells, symptoms for which they were being assessed at the departments of occupational and environmental medicine, in the university hospitals of Malmö and Lund, Sweden. Subjects with a history of long-term chemical exposure of neurotoxic significance were not included in this group. Patients with a traditional allergic reaction or medical or psychiatric disease, possible explanations for the main symptoms, were not included either. Further criteria for inclusion were intolerance to a multitude of chemical smells, symptoms elicited by very low but identifiable concentrations of chemical odors, and symptoms commonly associated with fatigue and exhaustion (eg, headache and dizziness) or of a multisystem type. Thus the aggregated criteria roughly fit the mainstream of case definitions applied in current research in the United States (9-11), as well as the suggestions of a workshop held by the World Health Organization (12). During a 5-year period, 26 patients were referred to the clinic for suspected multiple chemical sensitivity. Two persons declined participation. Of the 24 patients examined, 5 did not fulfill the criteria specified for multiple chemical sensitivity, and 2 were immigrants lacking the language skills necessary to understand questionnaires in Swedish. Of the 17 eligible patients, 14 agreed to participate in the challenges, and 13 of the 14 completed both challenges. As gender is known to be a strong determinant of self-rated annoyance (13), in order to simplify subsequent analyses, only the data of the female patients $(\mathrm{N}=10)$ have been included in this report. (See the Discussion.) Their mean age was 47 (SD 6) years, and their mean education was 11.1 (SD 2.4) years. Each subject with multiple chemical sensitivity was matched for gender, age, and level of education with two referents drawn from a pool of 102 female referents (14). The patient group has been described in more detail in previous studies of mental distress, personality, and neuropsychological functioning $(14,15)$.

Shortly before the challenge, all the subjects underwent a comprehensive medical work-up to ensure the absence of any other significant disease. The work-up was supplemented by health checks on the days of the exposure challenges. No temporary illness, not even a common cold, was permitted during the 2 -week period preceding the chamber challenges. The olfactory threshold had been quantitatively assessed months prior to the chamber challenge, through a procedure slightly modified from the one described by the Connecticut Chemosensory Clinical Research Center (16). N-butanol was used as the test odorant. The test proved all 30 subjects to be normosmic. Immediately after each exposure session, the olfactory thresholds were rechecked. Slight hyposmia was only detected for one subject in the reference group, and only after the second session (toluene). A supplementary qualitative check of olfactory function was also performed immediately before each challenge, using cocoa, coffee, peppermint oil, and namyl acetate (smells of banana). This procedure showed normal smell discrimination for all the subjects. The subjects were informed that all the exposures were below the current Swedish occupational exposure limits, and they were told about the total duration of the sessions. Details of the exposure design, such as the number or names of substances, were not disclosed until all the subjects had completed both sessions. The study was approved by the Ethics Committee of Lund University (LU 145-98, LU 236-94).

\section{Challenge design}

The exposure chamber had a volume of $2.15 \mathrm{~m}^{3}(1.03 \times$ $1.03 \times 2.03 \mathrm{~m})$. It had three walls of painted concrete and a glass front door. By a constant flow of air through a three-headed vessel containing the chemical, heated to a constant temperature, a stable primary air concentration was generated. By using a combination of valves, the primary mixture could be diluted with additional air to permit instantaneous alterations of the concentration. This mixture was led to a box below the chamber floor, containing winding channels, in order to create a final homogeneous mixture of room air and the chemical, entering the chamber through a $20-\mathrm{mm}$ wide slot along the entire rear side of the chamber. A slot $(0.57 \times 0.06 \mathrm{~m})$ in the center of the ceiling provided an outlet. The mixture was drawn into the chamber by the principle of underpressure, using a distantly placed fan connected to the outlet. The turnover rate was 96 /hour, corresponding to a mean air velocity in the chamber of $0.05 \mathrm{~m} / \mathrm{s}$. The mean chamber temperature during the sessions varied between 19.6 and $24.5^{\circ} \mathrm{C}$. The air concentration of the chemical was continuously monitored with an infrared spectrophotometer (Miran 1-A, Wilks Scientific Corp, South Norwalk, CN, USA) with the sampling nozzle in the approximate lateral center of the chamber, 0.4 meters below the ceiling. 
The basic experimental design has been described previously $(7,8)$. The only modification concerned the application of lower exposure levels for one of the substances, n-butyl acetate. Each subject completed two challenge sessions, one with exposure to n-butyl acetate and the other to toluene. The sessions were counterbalanced within the groups with respect to time of day (morning-afternoon), substance sequence, and test leader. The two sessions were scheduled 7 days apart at the same time of day. Each challenge session was divided into eight consecutive phases (figure 1). The first phase was a "prechamber phase" in normal air outside the chamber, followed by a "zero phase" in normal air inside the chamber. Next came a series of five phases with chemical exposure at increasing levels. The stepwise increase in the exposure levels served to counteract sensory adaptation effects. The final phase was without chemical exposure and served to acclimatize the subject to normal room air (data not presented). Exposure to n-butyl acetate started at $0.75 \mathrm{ppm}\left(3.6 \mathrm{mg} / \mathrm{m}^{3}\right)$ and followed a geometric progression scale with a ratio of two up to $12 \mathrm{ppm}\left(57 \mathrm{mg} / \mathrm{m}^{3}\right)$. Toluene exposure started at $3 \mathrm{ppm}\left(11 \mathrm{mg} / \mathrm{m}^{3}\right)$ and followed a geometric progression scale with a ratio of two up to $48 \mathrm{ppm}\left(180 \mathrm{mg} / \mathrm{m}^{3}\right)$. The duration of the chamber phases was 20 minutes at 0 (zero) ppm, 10 minutes at $0.75 \mathrm{ppm}$ for n-butyl acetate (or $3 \mathrm{ppm}$ for toluene), 10 minutes at $1.5 \mathrm{ppm}$ for (or $6 \mathrm{ppm}$ for toluene), 20 minutes at $3 \mathrm{ppm}$ for n-butyl acetate (or $12 \mathrm{ppm}$ for toluene), 10 minutes at $6 \mathrm{ppm}$ for n-butyl acetate (or $24 \mathrm{ppm}$ for toluene), 20 minutes at $12 \mathrm{ppm}$ for n-butyl acetate (or $48 \mathrm{ppm}$ for toluene), and finally 10 minures at $0 \mathrm{ppm}$. Typically, the air concentration stabilized within 4 minutes after each increase and varied less than $10 \%$ at each exposure level.

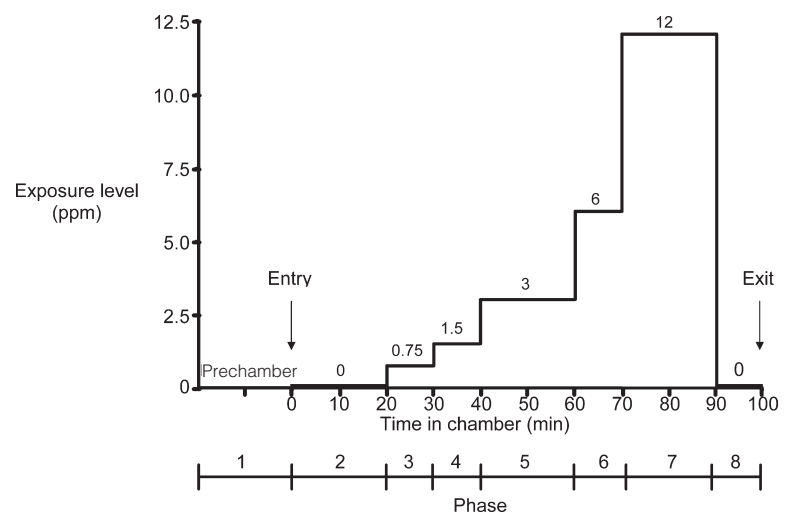

Figure 1. Phase duration and exposure levels during an exposure session with n-butyl acetate (exposure schedule excluding the delay during exposure increase and decrease). The exposure levels of toluene were four times higher.

\section{Challenge response}

In the chamber the subject was seated comfortably in front of a small tabletop, facing the glass door. The rating scales and reaction-time tests were presented on an outside 17-inch visual display unit (VDU) visible through the glass door, and they were responded to on a simplified keyboard. Identical equipment outside the chamber served to familiarize the subjects with the response procedures and to collect baseline data in the prechamber phase.

During each phase the subject rated smell intensity and several annoyance and irritation items. The administration was carried out with the programmable modules of The Automated Psychological Test System (APT) (17). Smell intensity was rated according to a seven-step Likert scale as none, very weak, weak, distinct, strong, very strong, or extremely strong (18). All the other questions were rated on visual analogue scales (range $0-100)$. Smell annoyance was analyzed separately. Due to the high intercorrelations between the remaining items, they were categorized into three indices. The items for irritation of eyes, mouth or throat, and nose were averaged to give an index of mucous membrane irritation. Ratings of drowsiness, headache, and concentration difficulties were averaged to give a fatigue index. Disturbances caused by other, nonsmell-related factors (ie, light, temperature, humidity, draft, and sound level) were averaged to give an environmental annoyance index.

The following three psychological performance tests were given during each of four phases, the prechamber phase, the zero phase, the fifth phase ( $3 \mathrm{ppm}$ of n-butyl acetate or $12 \mathrm{ppm}$ of toluene), and the seventh phase (12 ppm of n-butyl acetate or $48 \mathrm{ppm}$ of toluene):

1. The digit symbol test of the Wechsler Adult Intelligence Scale - Revised (WAIS-R) (19). For the present study, four parallel versions with different digit-symbol key combinations were used.

2. The APT two-way reaction-time test (RT2). The stimuli were white squares shown on the left or right side of the visual display unit, and the responses were given with either of two corresponding keys. The in dividual results were expressed in terms of level (the mean of the 50 reaction-time responses) and varia tion (the standard deviation of the 50 reaction-time responses).

3. The APT inhibition test (RT-inhib). This test is based on the RT2 test, but visual stimuli are accompanied by a simultaneous strong auditory signal occurring at random intervals (ratio 0.50). The subject was in structed to inhibit the habitual response if the auditory signal appeared. The individual results were 
expressed as for RT2, with the addition of an error ratio (false hits).

\section{Operationalizations of the hypotheses}

Several issues were addressed. First, expectancy or suggestion effects evoked by merely entering the chamber environment were studied by comparing the ratings and test performances in the two initial phases without chemical exposure, that is, the prechamber and zero phase.

Second, sensory-triggered strong immediate reactions were studied by comparing the increments in the ratings from the zero phase to the first true exposure phase. As this phase involves a very low air concentration of chemicals, it was unlikely to provoke annoyance or reduce the performance of healthy subjects, while, at the same time, resembling an everyday exposure situation that hypersensitive subjects typically describe as eliciting strong immediate reactions.

Third, dose-effect relationships were studied. For annoyance and intensity, the persons' slopes of increasing ratings across all the chamber phases were used. For the performance tests, the scores from the three chamber phases in which the tests were given were examined (phases 2, 5, and 7).

Fourth, a dimension of neurotoxicity was studied. To explore the possibility of a hypersensitivity of genuine neurotoxic origin, the subjects were exposed to the very faintly neurotoxic substance n-butyl acetate and the potent neurotoxicant toluene on two separate occasions. Toluene exposure was kept below the known thresholds for acute neurotoxic effects among healthy subjects. If the annoyance reactions of our patients were related to a genuine hypersensitivity to neurotoxins, a higher effect should have been found with toluene.

Fifth, session effects were studied (first versus second chamber session), to address the possibility of a different pattern of adaptation to the chamber challenges among our patients.

\section{Data analysis}

Data were analyzed with SPSS 10.0 for Windows (20). The four reaction-time variables were logarithmically transformed to comply with normality assumptions. All the data were analyzed with the SPSS general linear models repeated-measures analysis. A univariate full factorial four-way balanced model was used (ie, including all higher-order interactions, with type III sums of squares). The standard analysis model included the terms group (patients with multiple chemical sensitivity, referents) and exposure sequence (toluene then nbutyl acetate versus n-butyl acetate then toluene) as between-subject factors, and substance (n-butyl acetate, toluene) and phase (prechamber, zero, $12 \mathrm{ppm}$, and 48 ppm) as within-subject factors. This standard model was used in the analysis of test performance across chamber phases 2, 5 and 7. In the analyses of the ratings and performance tests in the initial phases without chemical exposure, the terms substance and exposure sequence were replaced by session (first versus second) to give a simpler three-way model. Preliminary analyses of ratings across all phases using the standard model revealed strong increases across all five rating scales or indices in both groups. To focus the analysis on the persons' patterns of increase for the ratings during the challenge to the chemicals, irrespective of baseline differences, the gradient of increasing ratings (ie, the slope steepness) was chosen as the most relevant dimension to study. Thus each subject's increase in the ratings across the chamber phases (ie, from the zero phase through the five steps of the geometric exposure increase) was examined with the "curve estimation" module of SPSS. This procedure showed that a linear regression equation provided the best fit for the individual rating slopes across the six chamber phases (with few exceptions highly statistically significant individual fits). Since the chamber phases were coded 1 to 6 and the exposure level increased geometrically, the resulting linear regression corresponded to an approximated log-linear function. Thus the slope steepness for each subject and substance was summarized in the beta coefficient. This procedure gave a three-way repeated-measures model, with group as the between-subjects factor and exposure sequence and substance as the within-subjects factors. The same three-way model was used to study sensory-triggered strong immediate reactions in the first phase of the chemical exposure, but beta was replaced with the person's rating increments from the preceding zero phase. Where appropriate, Greenhouse-Geisser-corrected results have been reported. In cases in which a statistically significant interaction of factors appeared in the repeated-measures analysis, $t$-tests (paired or independent due to the nature of the data) were used for further investigations. Statistical significance was assumed at an alpha level of $\mathrm{P}=0.05$.

\section{Results}

\section{Ratings scales}

Prechamber and zero phases. See table 1 and figures 25 for detailed information on the prechamber and zero phases. The smell intensity ratings were stable across the phases, sessions, and groups. The smell annoyance ratings showed an effect of phase, increasing slightly 
Table 1. Intensity and annoyance ratings during the initial phases of the study with no chemical exposure and the results of the repeated measures analyses.

\begin{tabular}{|c|c|c|c|c|c|c|c|c|c|c|c|c|}
\hline & \multicolumn{4}{|c|}{ Referents $(\mathrm{N}=20)$} & \multicolumn{4}{|c|}{ Patients $(\mathrm{N}=10)$} & \multicolumn{3}{|c|}{ P-values } & \multirow{3}{*}{$\begin{array}{l}\text { Interactions } \\
\text { with P-value } \\
<0.05\end{array}$} \\
\hline & \multicolumn{2}{|c|}{ Session 1} & \multicolumn{2}{|c|}{ Session 2} & \multicolumn{2}{|c|}{ Session 1} & \multicolumn{2}{|c|}{ Session 2} & \multicolumn{2}{|c|}{ Within subjects } & \multirow{2}{*}{$\begin{array}{l}\text { Between } \\
\text { subjects }\end{array}$} & \\
\hline & Mean & SD & Mean & SD & Mean & SD & Mean & SD & Phase & Session & & \\
\hline \multicolumn{13}{|l|}{ Smell intensity (1-7) } \\
\hline $\begin{array}{l}\text { Prechamber phase } \\
\text { Zero phase }\end{array}$ & $\begin{array}{l}1.4 \\
1.5\end{array}$ & $\begin{array}{l}0.7 \\
0.9\end{array}$ & $\begin{array}{l}1.3 \\
1.3\end{array}$ & $\begin{array}{l}0.4 \\
0.6\end{array}$ & $\begin{array}{l}1.5 \\
1.8\end{array}$ & $\begin{array}{l}0.8 \\
1.1\end{array}$ & $\begin{array}{l}1.3 \\
1.9\end{array}$ & $\begin{array}{l}0.7 \\
0.9\end{array}$ & 0.08 & 0.44 & 0.15 & None \\
\hline \multicolumn{13}{|c|}{ Smell annoyance $(0-100)$} \\
\hline $\begin{array}{l}\text { Prechamber phase } \\
\text { Zero phase }\end{array}$ & $\begin{array}{l}7.2 \\
9.2\end{array}$ & $\begin{array}{l}14.6 \\
19.1\end{array}$ & $\begin{array}{r}5.4 \\
11.6\end{array}$ & $\begin{array}{l}14.3 \\
19.0\end{array}$ & $\begin{array}{r}9.6 \\
22.8\end{array}$ & $\begin{array}{l}16.2 \\
26.4\end{array}$ & $\begin{array}{r}5.2 \\
16.6\end{array}$ & $\begin{array}{l}12.5 \\
22.0\end{array}$ & 0.01 & 0.19 & 0.37 & None \\
\hline \multicolumn{13}{|c|}{ Mucous membrane irritation $(0-100)$} \\
\hline $\begin{array}{l}\text { Prechamber phase } \\
\text { Zero phase }\end{array}$ & $\begin{array}{l}13.0 \\
17.2\end{array}$ & $\begin{array}{l}15.2 \\
19.2\end{array}$ & $\begin{array}{r}8.7 \\
12.0\end{array}$ & $\begin{array}{l}11.6 \\
16.8\end{array}$ & $\begin{array}{l}30.2 \\
35.9\end{array}$ & $\begin{array}{l}22.6 \\
23.3\end{array}$ & $\begin{array}{l}22.3 \\
31.7\end{array}$ & $\begin{array}{l}22.8 \\
27.7\end{array}$ & 0.02 & 0.03 & 0.01 & None \\
\hline \multicolumn{13}{|l|}{ Fatigue $(0-100)$} \\
\hline $\begin{array}{l}\text { Prechamber phase } \\
\text { Zero phase }\end{array}$ & $\begin{array}{r}7.3 \\
11.2\end{array}$ & $\begin{array}{l}10.4 \\
17.8\end{array}$ & $\begin{array}{r}7.4 \\
12.5\end{array}$ & $\begin{array}{l}13.3 \\
17.5\end{array}$ & $\begin{array}{l}15.6 \\
22.6\end{array}$ & $\begin{array}{l}16.6 \\
22.7\end{array}$ & $\begin{array}{l}25.5 \\
25.5\end{array}$ & $\begin{array}{l}24.6 \\
24.1\end{array}$ & 0.10 & 0.11 & 0.04 & None \\
\hline \multicolumn{13}{|c|}{ Environmental annoyance $(0-100)$} \\
\hline $\begin{array}{l}\text { Prechamber phase } \\
\text { Zero phase }\end{array}$ & $\begin{array}{l}9.9 \\
19.6^{\text {a }}\end{array}$ & $\begin{array}{l}13.2 \\
19.3\end{array}$ & $\begin{array}{l}8.4 \\
16.0^{b}\end{array}$ & $\begin{array}{l}13.5 \\
18.0\end{array}$ & $\begin{array}{l}16.0 \\
30.0^{a}\end{array}$ & $\begin{array}{l}21.7 \\
23.2\end{array}$ & $\begin{array}{l}16.3 \\
28.9^{b}\end{array}$ & $\begin{array}{l}23.9 \\
25.1\end{array}$ & $<0.001$ & 10.50 & 0.16 & None \\
\hline
\end{tabular}

a $P \leq 0.05$, posthoc t-test; prechamber phase compared with zero phase.

b $P \leq 0.005$, posthoc t-test; prechamber phase compared with zero phase.

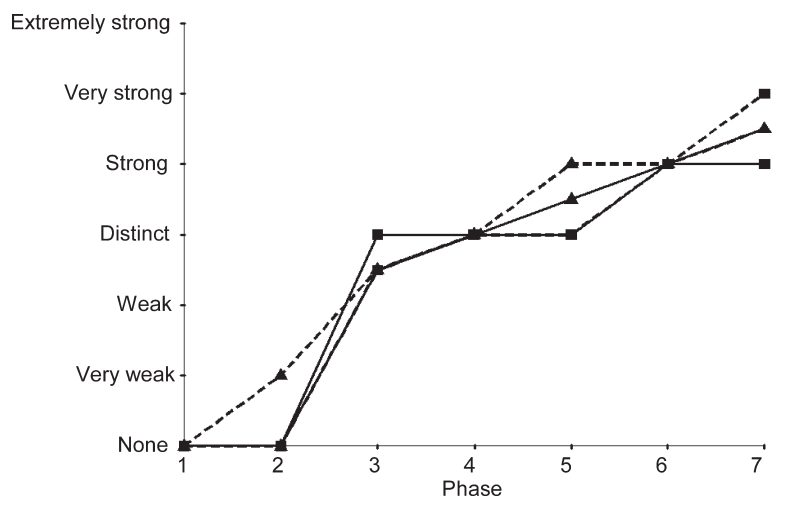

Figure 2. Smell intensity ratings (medians) during rising levels of exposure to n-butyl acetate (solid lines) and toluene (broken lines) for the subjects with multiple chemical sensitivity (triangles) and the referents (squares).

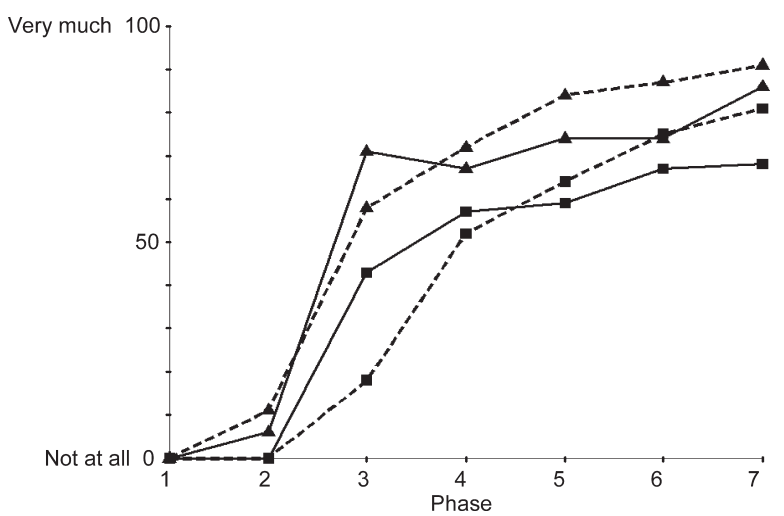

Figure 3. Smell annoyance ratings (medians) on a visual analogue scale during rising levels of exposure to n-butyl acetate (solid lines) and toluene (broken lines) for the subjects with multiple chemical sensitivity (triangles) and the referents (squares).

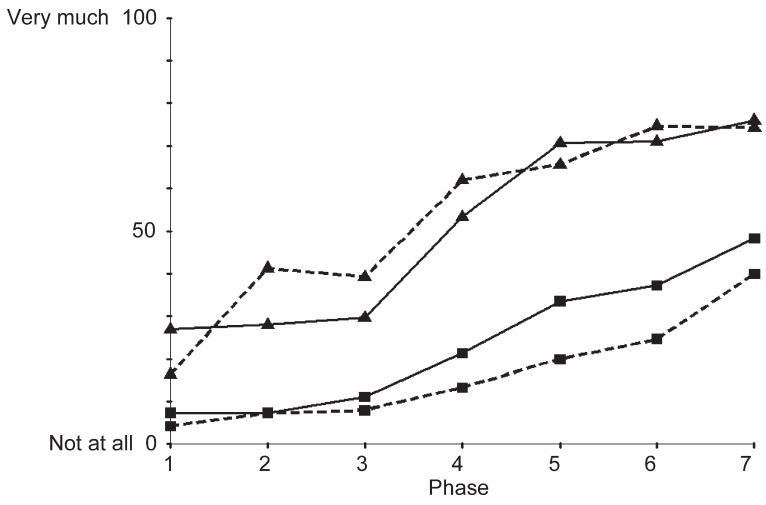

Figure 4. Ratings (medians) for mucous membrane irritation on a visual analogue scale during rising levels of exposure to n-butyl acetate (solid lines) and toluene (broken lines) for the subjects with multiple chemical sensitivity (triangles) and the referents (squares).

Very much 100

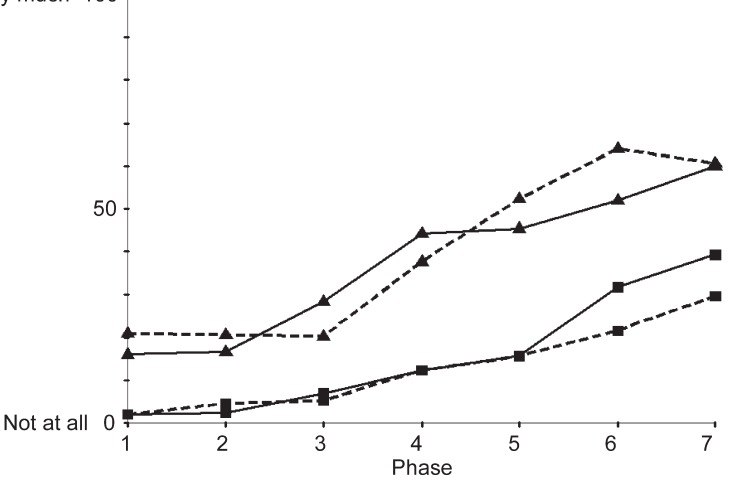

Figure 5. Ratings (medians) for fatigue on a visual analogue scale during rising levels of exposure to n-butyl acetate (solid lines) and toluene (broken lines) for the subjects with multiple chemical sensitivity (triangles) and the referents (squares). 
from the prechamber phase to the zero phase. The mucous membrane irritation ratings showed effects of phase, session, and group; the ratings were markedly higher among the patients than among the referents already in the prechamber phase, increased similarly in the two groups from the prechamber to the zero phase, and were generally lower in the second session. The fatigue ratings only showed an effect of group, with higher levels in the patient group (irrespective of phase). Annoyance to nonsmell-related factors (ie, the environmental annoyance index) was the dimension that showed the most marked effect of entering the chamber; the mean ratings on the visual analogue scales were approximately twice as high inside the chamber in both groups.

First exposure phase. The increase in the smell intensity and smell annoyance ratings from the zero phase to the first true exposure phase showed no relationship with substance, group, or exposure sequence. However, for smell annoyance and fatigue, a higher increment in the reactions was observed in the initial session than in the second (interaction substance by exposure sequence: smell annoyance, $\mathrm{P}=0.013$; fatigue, $\mathrm{P}=0.027$ ). The mean increment in the ratings on the visual analogue scale for smell annoyance was 37 during the first session versus 22 during the second (posthoc $\mathrm{P}=0.02$ ). For fatigue, the corresponding means were 17 and 7 , respectively (posthoc $\mathrm{P}=0.03$ ).

Chamber phases. See table 2 for information on the chamber phases. The smell intensity and smell annoyance ratings increased with similar slopes in both groups (figures 2 and 3). The ratings of mucous membrane irritation and fatigue showed steeper development among the patients than among the referents (figures 4 and 5).
There was no effect of substance or exposure sequence on the slope steepness for any of the five rating dimensions. Interaction of a magnitude reaching statistical significance was observed only for the fatigue index (substance by group by exposure sequence, $\mathrm{P}=0.03$ ), indicating that within the reference group a tendency towards a steeper fatigue slope during the second session than during the first was observed, bordering on significance posthoc $(\mathrm{P}=0.068$, paired $t$-test $)$.

\section{Performance tests}

Prechamber and zero phases. The RT2 level and variation increased (deteriorated) in both groups from the prechamber to the chamber zero phase, but the other test variables did not show any corresponding deterioration (table 3). There was also a general effect of session on the three RT-inhib variables and the digit symbol score, with higher performance in the second session (tables 4 and 5). In addition, the RT2 and RT-inhib variation and the RT-inhib level variables also showed an effect of group, representing a lower performance in the patient group irrespective of phase. Statistically significant interactions of phase by session appeared for the RT2 level and the three RT-inhib variables. This result indicates a more pronounced difference from the prechamber phase to the chamber zero phase in either the first or second session, but a coherent pattern was lacking. RT-inhib errors improved during the first session only $(\mathrm{P}=0.030)$. A statistically significant interaction effect phase by session by group for the RT2 level variable indicated that, for this variable, the phase effect was statistically significant only during the first session for the patient group and only

Table 2. Regression coefficients (beta) for the intensity and annoyance rating slopes during the chamber sessions with exposure to $n$ butyl acetate and toluene and the results of the repeated measures analyses. (ES=exposure sequence, Gr=group, Su=substance)

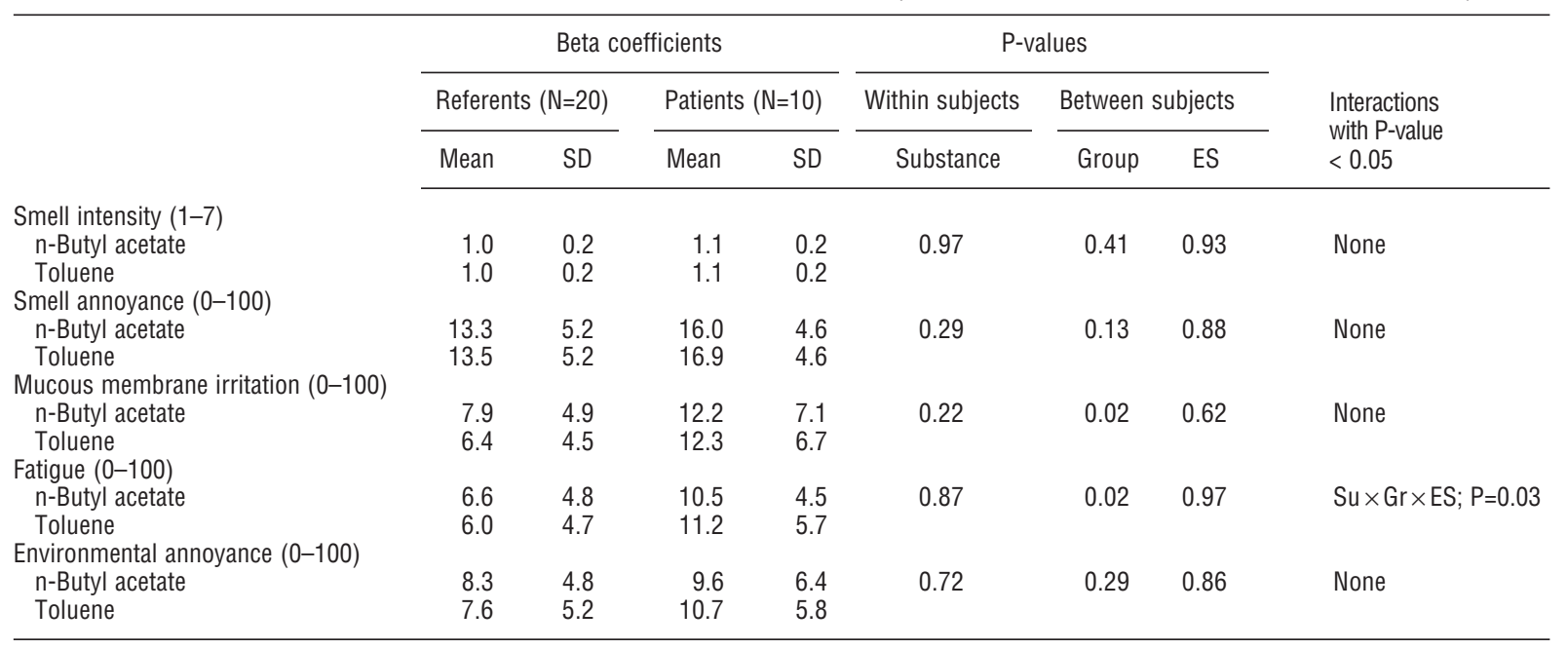


Table 3. Two-way reaction-time (RT2) scores for the Automated Psychological Test System during the prechamber phase, zero phase, and phases with exposure to n-butyl acetate and toluene and the results of the repeated-measures analyses. (ES=exposure sequence, $\mathrm{Gr}=$ group, $\mathrm{Ph}=$ phase, $\mathrm{Se}=$ session)

\begin{tabular}{|c|c|c|c|c|c|c|c|c|c|}
\hline \multirow{3}{*}{$\begin{array}{l}\text { Test } \\
\text { variable }\end{array}$} & & & & & \multicolumn{4}{|c|}{ P-values } & \multirow{3}{*}{$\begin{array}{l}\text { Interactions } \\
\text { with P-value }<0.05\end{array}$} \\
\hline & Referents $(\mathrm{N}=20)$ & & \multicolumn{2}{|c|}{ Patients $(\mathrm{N}=10)$} & \multicolumn{2}{|c|}{ Within subjects } & \multicolumn{2}{|c|}{ Between subjects } & \\
\hline & Mean & SD & Mean & SD & Phase & Substance & Group & ES & \\
\hline \multicolumn{10}{|l|}{ RT2 level (ms) } \\
\hline \multicolumn{10}{|l|}{ n-Butyl acetate } \\
\hline Prechamber & 325 & 59 & 352 & 49 & \multicolumn{5}{|c|}{ Prechamber phase versus zero phases } \\
\hline Zero phase & 353 & 59 & 405 & 75 & $<0.001$ & Se: 0.33 & 0.06 & - & $\mathrm{Ph} \times \mathrm{Se} ; \mathrm{P}=0.002$ \\
\hline 3 ppm phase & $377^{a}$ & 75 & 464 & 115 & & & & & \\
\hline 12 ppm phase & $379^{b}$ & 75 & 521 a, c & 163 & & & & & \\
\hline \multicolumn{10}{|l|}{ Toluene } \\
\hline Prechamber & 323 & 53 & 360 & 56 & \multicolumn{5}{|c|}{ Chamber phases } \\
\hline Zero phase & 356 & 60 & 396 & 38 & $<0.001$ & 0.86 & 0.01 & 0.74 & $\mathrm{Ph} \times \mathrm{Gr} ; \mathrm{P}=0.009$ \\
\hline 12 ppm phase & $391^{b}$ & 91 & $460^{a}$ & 66 & & & & & \\
\hline 48 ppm phase & $380^{a}$ & 90 & $488^{a}$ & 117 & & & & & \\
\hline \multicolumn{10}{|l|}{ RT2 variation (ms) } \\
\hline \multicolumn{10}{|l|}{ n-Butyl acetate } \\
\hline Prechamber & 61 & 21 & 75 & 20 & \multicolumn{5}{|c|}{ Prechamber versus zero phases } \\
\hline Zero phase & 75 & 31 & 99 & 58 & $<0.001$ & Se: 0.65 & 0.005 & - & $\mathrm{Ph} \times \mathrm{Se} \times \mathrm{Gr} ; \mathrm{P}=0.02$ \\
\hline 3 ppm phase & 88 & 52 & 100 & 31 & & & & & \\
\hline 12 ppm phase & 92 & 47 & $129^{c}$ & 53 & & & & & \\
\hline \multicolumn{10}{|l|}{ Toluene } \\
\hline Prechamber & 56 & 14 & 79 & 28 & \multicolumn{5}{|c|}{ Chamber phases } \\
\hline Zero phase & 66 & 17 & 105 & 51 & 0.001 & 0.57 & 0.01 & 0.16 & None \\
\hline 12 ppm phase & $99^{\text {a }}$ & 68 & 116 & 33 & & & & & \\
\hline 48 ppm phase & $93^{a}$ & 63 & $127^{a}$ & 43 & & & & & \\
\hline
\end{tabular}

a $\mathrm{P} \leq 0.05$, posthoc t-test; exposure phase compared with zero phase.

b $\mathrm{P} \leq 0.005$, posthoc t-test; exposure phase compared with zero phase.

c $\mathrm{P} \leq 0.05$, posthoc t-test; 12 ppm compared with 3 ppm (n-butyl acetate) or 48 ppm compared with 12 ppm (toluene).

during the second session for the reference group ( $\mathrm{P}=0.015$ and $\mathrm{P}=0.005$, respectively).

Chamber phases. RT2 level and variation and RT-inhib level increased (deteriorated) in both groups across the chamber phases (tables 3 and 4). The RT-inhib variation and error variables and the digit symbol scores were not clearly affected by phase (tables 4 and 5). Substance or exposure sequence had no effect on any of the test variables. Interaction phase by group was observed for the variables RT2 level, RT-inhib level, and the digit symbol score. This finding indicates a steeper increase in the reaction-time levels in the patient group, albeit statistically significant reaction-time increases across both groups and substances were seen only for the RT2 level variable posthoc. For digit symbol a trend towards successively improving (higher) scores was seen only in the reference group, but with a statistically significantly increased score versus the zero phase only in the final phase of the toluene condition. A further interaction substance by exposure sequence for the RT-inhib level and digit symbol score variables indicated better performance for these variables during the second session. The higher-order interaction phase by substance by exposure sequence appeared for the RT-inhib level and variation variables, indicating that increases occurred mainly (level) or exclusively (variation) during the second session.

\section{Discussion}

In our study, situational expectancy could not be demonstrated as a major factor behind acute symptom development in multiple chemical sensitivity. The initial chamber phase, during which the subjects did not know whether chemical exposure had begun or not (as verifiable by smell), induced only a slight increase in the mucous membrane irritation ratings, and some deterioration in the RT2 test, and these effects were seen in both the reference and the patient groups. Moreover, we did not observe a notably stronger response to the first few minutes of genuine chemical exposure in the patient group. However, across the full series of chamber phases the patients did show a steeper development of mucous membrane irritation and fatigue than the referents. Reaction times also deteriorated more in the patient group during the consecutive chamber phases, and only the reference group showed learning in the digit 
Table 4. Reaction-time (RT) scores for inhibition on the Automated Psychological Test System during the prechamber phase, zero phase, and phase with exposure to n-butyl acetate and toluene and the results of the repeated measures analyses. (ES=exposure sequence, $\mathrm{Gr}=$ group, $\mathrm{Ph}=$ phase, $\mathrm{Se}=$ session, $\mathrm{Su}=$ substance)

\begin{tabular}{|c|c|c|c|c|c|c|c|c|c|}
\hline \multirow{3}{*}{$\begin{array}{l}\text { Test } \\
\text { variable }\end{array}$} & \multirow{2}{*}{\multicolumn{2}{|c|}{ Referents $(\mathrm{N}=20)$}} & \multirow{2}{*}{\multicolumn{2}{|c|}{ Patients $(\mathrm{N}=10)$}} & \multicolumn{4}{|c|}{ P-values } & \multirow{3}{*}{$\begin{array}{l}\text { Interactions with } \\
\text { P-value }<0.05\end{array}$} \\
\hline & & & & & \multicolumn{2}{|c|}{ Within-subjects } & \multicolumn{2}{|c|}{ Between-subjects } & \\
\hline & Mean & SD & Mean & SD & Phase & Substance & Group & ES & \\
\hline \multicolumn{10}{|c|}{$\begin{array}{l}\text { RT inhibition level (ms) } \\
\text { n-Butyl acetate }\end{array}$} \\
\hline $\begin{array}{l}\text { Prechamber } \\
\text { Zero phase } \\
3 \mathrm{ppm} \\
12 \mathrm{ppm}\end{array}$ & $\begin{array}{l}407 \\
398 \\
400 \\
400\end{array}$ & $\begin{array}{r}89 \\
91 \\
100 \\
91\end{array}$ & $\begin{array}{l}468 \\
469 \\
519 \\
554\end{array}$ & $\begin{array}{l}116 \\
129 \\
127 \\
168\end{array}$ & \multicolumn{5}{|c|}{$\begin{array}{l}\text { Prechamber phase versus zero phases } \\
\text { Se: }<0.001 \quad 0.02 \quad-\quad P \quad P h \times S e ; P=0.01\end{array}$} \\
\hline \multicolumn{10}{|l|}{ Toluene } \\
\hline $\begin{array}{l}\text { Prechamber } \\
\text { Zero phase } \\
12 \text { ppm } \\
48 \text { ppm }\end{array}$ & $\begin{array}{l}405 \\
401 \\
421 \\
406\end{array}$ & $\begin{array}{r}97 \\
78 \\
116 \\
110\end{array}$ & $\begin{array}{l}473 \\
508 \\
519 \\
581\end{array}$ & $\begin{array}{r}76 \\
82 \\
76 \\
156\end{array}$ & 0.03 & 0.12 & $\begin{array}{r}\text { Chamber } \\
0.002\end{array}$ & es 0.79 & $\begin{array}{l}\mathrm{Ph} \times \mathrm{Gr} ; \mathrm{P}=0.04 \\
\mathrm{Su} \times \mathrm{ES} ; \mathrm{P}=0.003 \\
\mathrm{Ph} \times \mathrm{Su} \times \mathrm{ES} ; \mathrm{P}=0.02\end{array}$ \\
\hline \multicolumn{10}{|c|}{$\begin{array}{l}\text { RT inhibition variation (ms) } \\
\text { n-Butyl acetate }\end{array}$} \\
\hline $\begin{array}{l}\text { Prechamber } \\
\text { Zero phase } \\
3 \mathrm{ppm} \\
12 \mathrm{ppm}\end{array}$ & $\begin{array}{l}78 \\
77 \\
85 \\
95\end{array}$ & $\begin{array}{l}37 \\
38 \\
79 \\
76\end{array}$ & $\begin{array}{l}105 \\
102 \\
119 \\
123\end{array}$ & $\begin{array}{l}41 \\
72 \\
48 \\
80\end{array}$ & \multicolumn{5}{|c|}{$\begin{array}{l}\text { Prechamber versus zero phases } \\
\text { Se: }<0.001 \quad 0.015\end{array}$} \\
\hline \multicolumn{10}{|l|}{ Toluene } \\
\hline $\begin{array}{l}\text { Prechamber } \\
\text { Zero phase } \\
12 \mathrm{ppm} \\
48 \mathrm{ppm}\end{array}$ & $\begin{array}{r}81 \\
75 \\
108 \\
88\end{array}$ & $\begin{array}{l}50 \\
30 \\
96 \\
67\end{array}$ & $\begin{array}{r}98 \\
125 \\
118 \\
163\end{array}$ & $\begin{array}{r}29 \\
63 \\
45 \\
118\end{array}$ & \multicolumn{5}{|c|}{$\begin{array}{cc}\text { Chamber phases } \\
0.02 \quad 0.64\end{array}$} \\
\hline \multicolumn{10}{|c|}{$\begin{array}{l}\text { RT-inhibition error ratio (\%) } \\
\text { n-Butyl acetate }\end{array}$} \\
\hline $\begin{array}{l}\text { Prechamber } \\
\text { Zero phase } \\
3 \mathrm{ppm} \\
12 \mathrm{ppm}\end{array}$ & $\begin{array}{l}3.2 \\
2.2 \\
2.8 \\
2.4\end{array}$ & $\begin{array}{l}3.1 \\
2.7 \\
3.9 \\
2.7\end{array}$ & $\begin{array}{l}2.4 \\
2.8 \\
2.8 \\
2.4\end{array}$ & $\begin{array}{l}3.4 \\
3.8 \\
3.8 \\
2.8\end{array}$ & \multicolumn{5}{|c|}{$\begin{array}{l}\text { Prechamber versus zero phases } \\
\text { Se: }<0.001 \quad 0.62\end{array}$} \\
\hline \multicolumn{10}{|l|}{ Toluene } \\
\hline $\begin{array}{l}\text { Prechamber } \\
\text { Zero phase } \\
12 \text { ppm } \\
48 \text { ppm }\end{array}$ & $\begin{array}{l}4.0 \\
3.0 \\
2.6 \\
2.4\end{array}$ & $\begin{array}{l}3.7 \\
3.6 \\
3.3 \\
3.3\end{array}$ & $\begin{array}{l}4.4 \\
1.2 \\
2.0 \\
2.4\end{array}$ & $\begin{array}{l}4.8 \\
1.9 \\
2.1 \\
2.8\end{array}$ & \multicolumn{5}{|c|}{$\begin{array}{cc}\text { Chamber phases } \\
0.69 \quad 0.40\end{array}$} \\
\hline
\end{tabular}

Table 5. Raw scores on the digit symbol test of the Wechsler Adult Intelligence Scale-Revised during the prechamber phase, zero phase, and phase with exposure to n-butyl acetate and toluene and the results of repeated-measures analyses of variance. (ES=exposure sequence, $\mathrm{Gr}=$ group, $\mathrm{Ph}=$ phase, $\mathrm{Se}=$ session, Su=substance)

\begin{tabular}{|c|c|c|c|c|c|c|c|c|c|}
\hline \multirow{3}{*}{ Exposure } & & & & & \multicolumn{4}{|c|}{ P-values } & \multirow{3}{*}{$\begin{array}{l}\text { Interactions } \\
\text { with } \mathrm{P} \text {-value }<0.05\end{array}$} \\
\hline & \multicolumn{2}{|c|}{ Referents $(\mathrm{N}=20)$} & \multicolumn{2}{|c|}{ Patients $(\mathrm{N}=10)$} & \multicolumn{2}{|c|}{ Within subjects } & \multicolumn{2}{|c|}{ Between subjects } & \\
\hline & Mean & SD & Mean & SD & Phase & Substance & Group & ES & \\
\hline \multicolumn{10}{|l|}{ n-Butyl acetate } \\
\hline Prechamber & 66.0 & 8.9 & 64.3 & 11.9 & \multicolumn{4}{|c|}{ Prechamber phase versus zero phases } & \\
\hline Zero phase & 66.8 & 8.8 & 63.8 & 12.4 & 0.31 & Se: $<0.001$ & 0.52 & - & None \\
\hline 3 ppm phase & 67.8 & 7.4 & 61.4 & 12.9 & & & & & \\
\hline 12 ppm phase & 69.1 & 7.3 & $63.9^{a}$ & 13.5 & & & & & \\
\hline \multicolumn{10}{|l|}{ Toluene } \\
\hline Prechamber & 65.4 & 8.3 & 63.6 & 10.2 & \multicolumn{4}{|c|}{ Chamber phases } & \\
\hline Zero phase & 66.6 & 7.1 & 64.8 & 9.3 & 0.23 & 0.65 & 0.16 & 0.89 & $\mathrm{Ph} \times \mathrm{Gr} ; \mathrm{P}=0.04$ \\
\hline $12 \mathrm{ppm}$ phase & 67.4 & 8.2 & 61.6 & 12.3 & & & & & Su $\times E S ; P<0.001$ \\
\hline $48 \mathrm{ppm}$ phase & $68.6^{b}$ & 8.8 & 61.6 & 14.6 & & & & & \\
\hline
\end{tabular}

a $P \leq 0.05$, posthoc t-test; $12 \mathrm{ppm}$ compared with $3 \mathrm{ppm}$ (n-butyl acetate) or $48 \mathrm{ppm}$ compared with $3 \mathrm{ppm}$ (toluene).

b $\mathrm{P} \leq 0.05$, posthoc $\mathrm{t}$-test; exposure phase compared with zero phase. 
symbol test. On the other hand, the smell intensity ratings (irrespective of annoyance) showed a strikingly similar development across groups throughout the series of exposure steps.

Annoyance was found to be unrelated to the neurotoxic properties of the two substances. Toluene was not perceived as stronger or more annoying than n-butyl acetate, in spite of the acutely neurotoxic properties of toluene and the fourfold air concentrations used. Congruent results were found in the performance tests. These results discourage an acute neurotoxic effect on the central nervous system as the explanatory mechanism behind the symptoms of multiple chemical sensitivity.

Although both groups of women displayed some degree of declining test performance during chemical provocation, the decline observed in the patient group was more pronounced. Such a drop in performance was not found among men with toxic encephalopathy and intolerance to chemical smells in our similarly designed previous study (8). However, the toxic encephalopathy group showed a similar pattern of steeper development of fatigue and mucous membrane irritation during the chamber phases, when each patient group was compared with their respective gender-matched reference group (7). Some more general findings, irrespective of group, replicated in our present study, were the previously observed generally lower test performance during the first challenge session and the higher mucous membrane annoyance ratings during the initial phases without exposure of the first challenge session. Our present study also showed that the increments in the ratings of smell intensity and fatigue during the first phase of the chemical exposure were generally higher in the first challenge session when the subjects faced the novelty of the situation. This finding suggests that tension and expectancy have an impact on ratings, a finding congruent with the notion of emotional state as a possible modifier of the subjective perception of chemical smells and other environmental factors $(21,22)$. However, the general decrease in such psychological reactions from the first to the second session, observed in both groups, does not support the hypothesis that people with multiple chemical sensitivity would have a deviating habituation response to repeated exposures.

A more peripheral observation concerns the marked gender differences in the annoyance ratings when the present female referents were compared with the male referents in our previous challenge study $(7,8)$. The women showed a steeper increase in ratings across most of the annoyance dimensions during the chamber sessions, a fact which stresses not only the importance of gender matching in the design of chemical challenge studies, but also the general significance of gender when reports of annoyance attributed to environmental factors are evaluated (23).
Our present study suggests that people with multiple chemical sensitivity have a similar increase in annoyance reactions during experimental chemical challenge as patients with toxic encephalopathy with many years of occupational solvent exposure. The smell intolerance in toxic encephalopathy can be regarded as a learned response due to a prolonged experience of associating chemical smells with acute neurotoxic symptoms (24). Possibly, the compromised functioning of the nervous system and the resulting asthenia characteristic of toxic encephalopathy might also enhance the vulnerability for such learning or lower the tolerance for its effects. It is less obvious how a learning process may apply to the syndrome of multiple chemical sensitivity, as it develops even after cumulated exposures to chemicals and smells far below levels of neurotoxic significance. Very intense or noxious unconditioned stimuli, highly aroused or neurotic subjects, and a longer passage of time between learning and testing have been suggested as factors that may arrest the natural extinction process or even give a paradoxically increased response $(25,26)$ and may trigger sensitization instead of habituation (27). In our present study, the group with multiple chemical sensitivity showed longer reaction times already at the beginning of the study, replicating the previous finding of isolated deviations in reactiontime tests in a neuropsychological screening of a larger group of patients with multiple chemical sensitivity (15). It is unclear whether this finding indicates the presence of a subtle brain dysfunction in multiple chemical sensitivity. A vulnerability to conditioning and sensitization due to a deviation in the functioning of the limbic system has been suggested (28). Such vulnerability could be explained in different ways. Speculatively, it may be constitutional or it may be due to long-term mental overload —or a mixture of both $(4,29)$.

Another possible explanation is that the condition of multiple chemical sensitivity represents a somatization disorder or panic disorder $(6,30)$. From this perspective, higher annoyance-both in the baseline procedure and in terms of reactivity to chemical challenge-may reflect personality factors, such as high trait anxiety, or strong beliefs about the hazardousness of chemicals and other environmental agents $(31,32)$. Some challenge experiments have indeed given results indicative of easily provoked psychogenic mechanisms like panic attacks or symptom attribution among most patients with multiple chemical sensitivity $(5,6)$. Although the comparability of the results may be limited due to the obvious differences in purpose and methodology, our present findings seem to stand in contrast to the findings of these previous studies. We did not observe a single case of demonstrative behavior or panic during the chamber sessions. Moreover, our group with multiple chemical sensitivity showed neither abnormal initial 
expectancy reactions nor extreme reactions to the first minutes of weak exposure. In these respects the group of female patients with multiple chemical sensitivity had a response pattern close to that of the female referents. A reservation must possibly be made for the fact that the patients with multiple chemical sensitivity had a higher "baseline" level of complaintsexpected and typical for both multiple chemical sensitivity and toxic encephalopathy $(7,14)$ - which may have masked the full potential of reactions during the chemical challenges. One possible explanation for the divergent outcomes may be variations in the selection criteria applied: We took care not to include any smellintolerant patients with suspected psychiatric disorder in our group of subjects with multiple chemical sensitivity. We have, in a previous study, also empirically verified that personality deviation, psychiatric disease, or elevated risk perception were not characteristic of our group of patients with multiple chemical sensitivity (14). Because our sample of patients with multiple chemical sensitivity was small, and did not include men, our findings should be interpreted with caution and should preferably be replicated in a larger group of patients.

\section{Acknowledgments}

The Swedish Council for Work Life Research supported the study grants 94-154 and 97-925. Thanks are due to psychologists Lena Seger, MSc, Anne-Li Hallin, MSc, Cecilia Bergh, MSc, and Roger Persson, PhD, for their skillful assistance with the data sampling. Karin Paulsson is thanked for her assistance with running the exposure chamber.

\section{References}

1. Sparks PJ. Idiopathic environmental intolerances: overview. Occup Med 2000;15:497-510.

2. Giardino ND, Lehrer PM. Behavioral conditioning and idiopathic environmental intolerance. Occup Med 2000;15:51928.

3. Bell IR, Schwartz GE, Baldwin CM, Hardin EE, Klimas NG, Kline JP, et al. Individual differences in neural sensitization and the role of context in illness from low-level environmental chemical exposures. Environ Health Perspect 1997;105 Suppl 2:457-66.

4. Eriksen HR, Ursin H. Sensitization and subjective health complaints. Scand J Psychol 2002;43:189-96.

5. Staudenmayer H, Selner JC, Buhr MP. Double-blind provocation chamber challenges in 20 patients presenting with "Multiple chemical sensitivity". Regul Toxicol Pharmacol 1993;18:44-53.
6. Leznoff A, Binkley KE. Idiopathic environmental intolerances: results of challenge studies. Occup Med 2000;15:529-37.

7. Ørbæk P, Österberg K, Åkesson B, Bergendorf U, Karlson B, Seger L. Suprathreshold intensity and annoyance reactions in experimental challenge to toluene and n-butyl acetate among subjects with long-term solvent exposure. Scand J Work Environ Health 1998;24:432-8.

8. Österberg K, Ørbæk P, Karlson B, Seger L, Åkesson B, Bergendorf U. Psychological test performance during experimental challenge to toluene and n-butyl acetate in cases of solvent-induced toxic encephalopathy. Scand J Work Environ Health 2000;26:219-26.

9. Bartha L, Baumzweiger W, Buscher DS, Callender MD, Dahl KA, Davidoff A, et al. Multiple chemical sensitivity: a 1999 consensus. Arch Environ Health 1999;54(3):147-9.

10. Nethercott JR, Davidoff LL, Curbow B, Abbey H. Multiple chemical sensitivities syndrome: toward a working case definition. Arch Environ Health 1993;48(1):19-26.

11. National Research Council (NRC). Multiple chemical sensitivities: addendum to biologic markers in immunotoxicology. Washington (DC): National Academy Press; 1992.

12. - Report of multiple chemical sensitivities (MCS) workshop: international programme on chemical safety (IPCS): German workshop on multiple chemical sensitivities. Int Arch Occup Environ Health 1997;69:224-6.

13. Gijsbers Van Wijk CM, Kolk AM. Sex differences in physical symptoms: the contribution of symptom perception theory. Soc Sci Med 1997;45:231-46.

14. Österberg K, Karlson B, Ørbæk P. Personality, mental distress, and risk perception in subjects with multiple chemical sensitivity and toxic encephalopathy. Scand J Psychol 2002; 43:169-75.

15. Österberg K, Ørbæk P, Karlson B. Neuropsychological test performance in Swedish multiple chemical sensitivity patients-an exploratory study. Appl Neuropsychol. In press.

16. Cain WS. Testing olfaction in a clinical setting. Ear Nose Throat J 1989;68(4):316, 322-8.

17. Levander S, Elithorn A. The automated psychological test system: manual. Trondheim (Norway): Department of psychiatry and behavioral medicine, University of Trondheim; 1987.

18. Winneke G. Structure and determinants of psychophysiological response to odorant/irritant air pollution. Ann NY Acad Sci 1992;641:261-76.

19. Wechsler D. Wechsler adult intelligence scale-revised: manual. Stockholm: Psykologiförlaget; 1992.

20. SPSS Inc. Statistical package for the social sciences (SPSS), version 10.0. Chicago (IL): SPSS Inc; 2000.

21. Dalton P, Wysocki CJ, Brody MJ, Lawley HJ. The influence of cognitive bias on the perceived odor, irritation and health symptoms from chemical exposure. Int Arch Occup Environ Health 1997;69:407-17.

22. Dalton P. Cognitive influences on health symptoms from acute chemical exposure. Health Psychol 1999;18:579-90.

23. Stenberg B, Wall S. Why do women report 'sick building symptoms' more often than men? Soc Sci Med 1995;40:491502.

24. Bolla-Wilson K, Wilson RJ, Bleecker ML. Conditioning of physical symptoms after neurotoxic exposure. J Occup Med 1988;30:684-6.

25. Van den Bergh O, Stegen K, Van Diest I, Raes C, Stulens P, Eelen $\mathrm{P}$, et al. Acquisition and extinction of somatic symptoms in response to odours: a Pavlovian paradigm relevant to multiple chemical sensitivity. Occup Environ Med 1999; 
56:295-301.

26. Van den Bergh O, Winters W, Devriese S, Van Diest I. Learning subjective health complaints. Scand J Psychol 2002; 43:147-52.

27. Overmier B. Sensitization, conditioning, and learning: can they help us understand somatization and disability? Scand J Psychol 2002;43:105-12.

28. Bell IR, Baldwin CM, Russek LG, Schwartz GE, Hardin EE. Early life stress, negative paternal relationships, and chemical intolerance in middle-aged women: support for a neural sensitization model. J Womens Health 1998;7:1135-47.

29. Bell IR, Baldwin CM, Fernandez M, Schwartz GE. Neural sensitization model for multiple chemical sensitivity: over- view of theory and empirical evidence. Toxicol Ind Health 1999;15:295-304.

30. Black DW. The relationship of mental disorders and idiopathic environmental intolerance. Occup Med 2000;15: 557-70.

31. Seeber A, Demes P, Golka K, Kiesswetter E, Schaper M, van Thriel C, et al. Subjective symptoms due to solvent mixtures, dioxin, and toluene: impact of exposure versus personality factors. Neurotoxicology 2000;21:677-84.

32. Dalton P. Odor perception and beliefs about risk. Chem Senses 1996;21:447-58.

Received for publication: 19 July 2002 